\title{
Influence of the physical state of water in the diffusion process in asphalt binders
}

\author{
Kamilla L. Vasconcelos ${ }^{1}$, Amit Bhasin ${ }^{2}$, Dallas N. Little ${ }^{3}$ e Charles N. Glover ${ }^{4}$
}

\begin{abstract}
Moisture damage in asphalt mixtures is a complex phenomenon that involves mechanical, chemical, physical and thermodynamic processes. This damage contributes significantly to the premature deterioration of asphalt pavements, which leads to extra cost in highway maintenance and vehicle operations. One key mechanism of how moisture reaches the asphalt-aggregate interface is by its permeation or diffusion through the asphalt binder or mastic. For the asphalt-water system studied, the Fourier Transform Infrared (FTIR) - Attenuated Total Reflectance (ATR) spectrometry was used. Water shows strong absorption in the infrared region and the FTIR-ATR technique has the ability to monitor both the kinetics of moisture ingress as well as any chemical changes occurring during the test. This paper has the literature review and some results obtained in the comparison between water diffusion in the liquid state with the moisture (or vapor) state, both at room temperature. DOI:10.4237/transportes.v20i4.619.
\end{abstract}

Keywords: asphalt mixtures, moisture damage, diffusion, spectroscopy.

\section{INTRODUCTION AND BACKGROUND}

There are three potential ways by which moisture can reach the asphalt-aggregate interface: (i) defect on asphalt coating, (ii) residual moisture present into the aggregates, and (iii) diffusion through the asphalt/mastic (Figure 1). The diffusion coefficient is dependent on the rate of moisture infiltration towards the asphalt-aggregate interface, and is an indicator of the time scale over which the moisture damage occurs.

Different experimental setups have been used to measure moisture diffusion or permeation in asphalt materials. However, the influence of the physical state of water in the diffusion measurements has yet to be analyzed in more detail. Some studies have considered water in the liquid state (Cheng et al. 2003; Kassem et al. 2006; Nguyen et al. 2005; Wei 2009); others controlled the relative humidity of the environment in contact with the sample to simulate water in the vapor or molecular form (Arambula et al. 2010; Kringos et al. 2008; Sasaki et al. 2006).

The three diagrams below (Figure 2) illustrate the distinct arrangement patterns of water molecules as they change their physical state from ice to water to gas. Frozen water molecules arrange themselves in a particular highly organized rigid geometric pattern that causes the mass of water to expand and to decrease in density. In the liquid phase, water molecules arrange themselves into small groups of joined particles. The fact that these arrangements are small allows liquid water to move and flow. Water molecules in the form of a gas are highly energized. This high energy state sets the molecules in continuous movement reducing the likelihood of the formation of bonds between

\footnotetext{
${ }^{1}$ Kamilla L. Vasconcelos, Department of Transportation Engineering, Polytechnic School, University of São Paulo, São Paulo, SP, Brazil. (e-mail: kamilla.vasconcelos@gmail.com).

${ }^{2}$ Amit Bhasin, Department of Civil, Architectural and Environmental Engineering, University of Texas, Austin, USA.

${ }^{3}$ Dallas N. Little, Zachary Department of Civil Engineering, Texas A\&M University, Austin, USA.

${ }^{4}$ Charles N. Glover, Artie McFerrin Department of Chemical Engineering,
} Texas A\&M University, Austin, USA.

Manuscrito recebido em 29/8/2012 e aprovado para publicação em 18/10/2012. Este artigo é parte de TRANSPORTES v. 20, n. 4, 2012. ISSN: 2237-1346 (online). DOI:10.4237/transportes.v20i4.619.

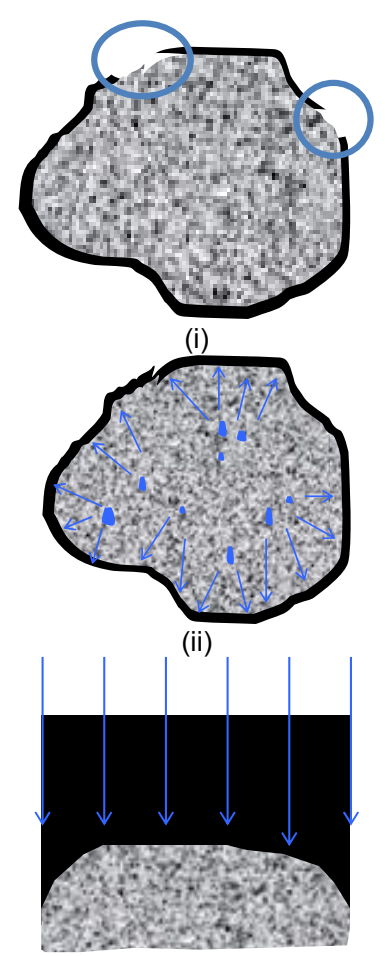

(iii)

Figure 1. Potential Forms by which the Moisture can Reach the Asphalt/Aggregate Interface: (i) Defect on Asphalt Coating, (ii) Wet Aggregates, and (iii) Diffusion through the Asphalt/Mastic

individual molecules.

The literature describes water diffusion in several types of polymeric materials. Previous research proved that for liquids in polymeric materials, sorbed volumes can be 10 to $20 \%$ or even higher, compared to gas-polymer systems where sorbed volumes are vanishingly small in most cases (Wolf 1991). According to Wolf, liquids open up the structure, with the result that the absolute flux rates through a membrane can be 2 to 3 orders of magnitude higher for a liquid than for a non-condensable gas. The water molecule has the ability to form hydrogen bonds with other water molecules and/or polar groups in the polymer. The diffusion coefficient may increase with increasing concentration, for hydrophilic polymers, or vary inversely for hydrophobic polymers.

The authors have not been able to find studies referenced 


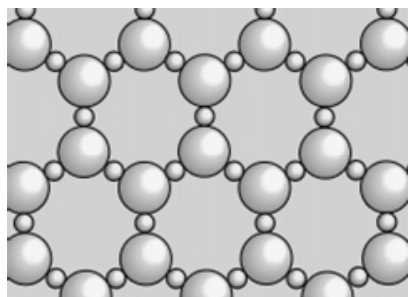

(a)

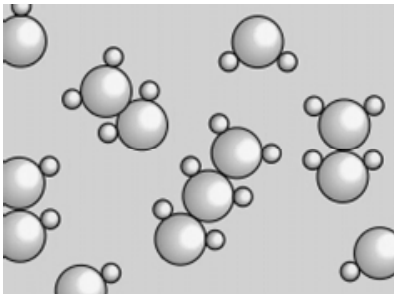

(b)

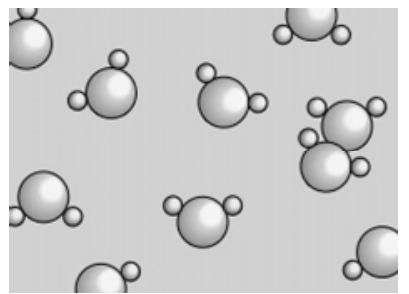

(c)

Figure 2. Arrangement Patterns of Water Molecules at Different Physical States: (a) Ice, (b) Liquid, (c) Vapor

in the literature that compare the diffusion coefficient for the same material, using the same experiment setup, but varying the physical state of water only. We do know that water spectrum has very different configuration in the ice, liquid and vapor states, and this produces completely different spectra when subjected to molecular vibration (Ewing et al. 2003). The objective of this paper is to use the Fourier Transform Infrared - Attenuated Total Reflectance (FTIR-ATR) technique to evaluate water (under liquid and vapor form) diffusion in asphalt binders. The technique allows the differentiation between both modes of moisture transport.

\subsection{FTIR-ATR spectra of water in liquid and vapor form}

FTIR-ATR spectroscopy has been used with increasing frequency to examine diffusion in polymers, with investigations covering a diverse array of applications. It is a technique that sets itself apart from other techniques with its ability to sensitively distinguish between different chemical species by providing molecular-level contrast between solutes and polymers based on absorbing light at different wavelengths or vibrational bond energies.

The water absorption bands are related to molecular vibrations involving different combinations of the three fundamental vibration transitions: (i) $v_{1}$ (symmetric stretch mode at $3277 \mathrm{~cm}^{-1}$ ), (ii) $v_{2}$ (bending mode at $1645 \mathrm{~cm}^{-1}$ ), and (iii) $v_{3}$ (asymmetric stretch mode at $3490 \mathrm{~cm}^{-1}$ ), all illustrated in Figure 3. The dipole moments change in the direction of the movement of the oxygen atoms as shown by the arrows.

The water molecule has a very small moment of inertia on rotation which gives rise to rich combined vibrationalrotational spectra in the vapor containing many spectral lines. In the liquid, rotations tend to be restricted by hydrogen bonds, giving the librations (vibrations before coming to a total rest). Also, spectral lines are broader causing overlapping of many absorption peaks. Figure 4 illustrates the water spectra in the vapor and liquid form at different temperatures. Ewing et al. (2003) presented the spectra for water and vapor at $25^{\circ} \mathrm{C}$, Figure 5 , and the results were similar to the results presented in Figure 4. Increased strength of hydrogen bonding, observed from the vapor to the liquid state, typically shifts the stretch vibration (represented in the region around $3400 \mathrm{~cm}^{-1}$ ) to lower frequencies with greatly increase intensity in the absorbance results (Figure 5).

Hydrogen bonds in liquid water have a broad, smooth, single-peaked distribution of strengths which gradually shifts with temperature. An increase in temperature causes a gradual shift in the direction of the vapor frequency (Figure 5). At one end of the distributions are hydrogen bonds having strengths comparable with those of hydrogen bonds in ice (Bertie et al. 1969). At the other end are very weak hydrogen bonds, which correspond to the small but appreciable absorption at frequencies approaching those of non-

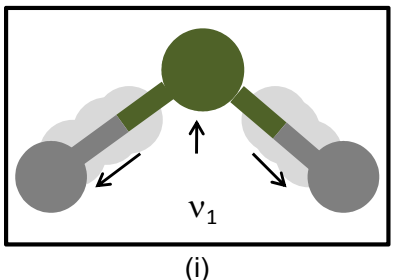

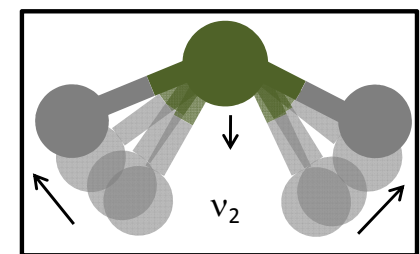

(ii)

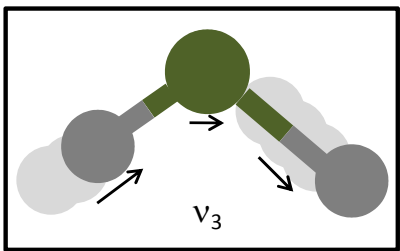

(iii)

Figure 3. Fundamental Vibration Transitions: (i) Symmetric Stretching, (ii) Bending, and (iii) Asymmetric Stretching

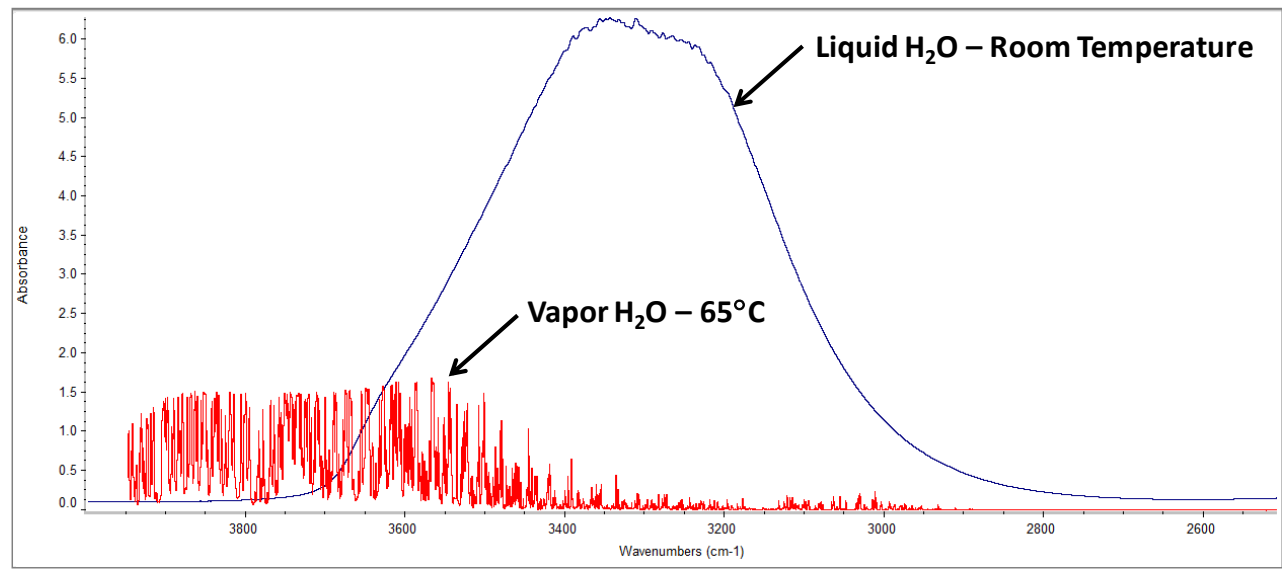

Figure 4. Comparison of Water Spectra in Vapor and Liquid Form (Source: Termo Fischer Scientific) 


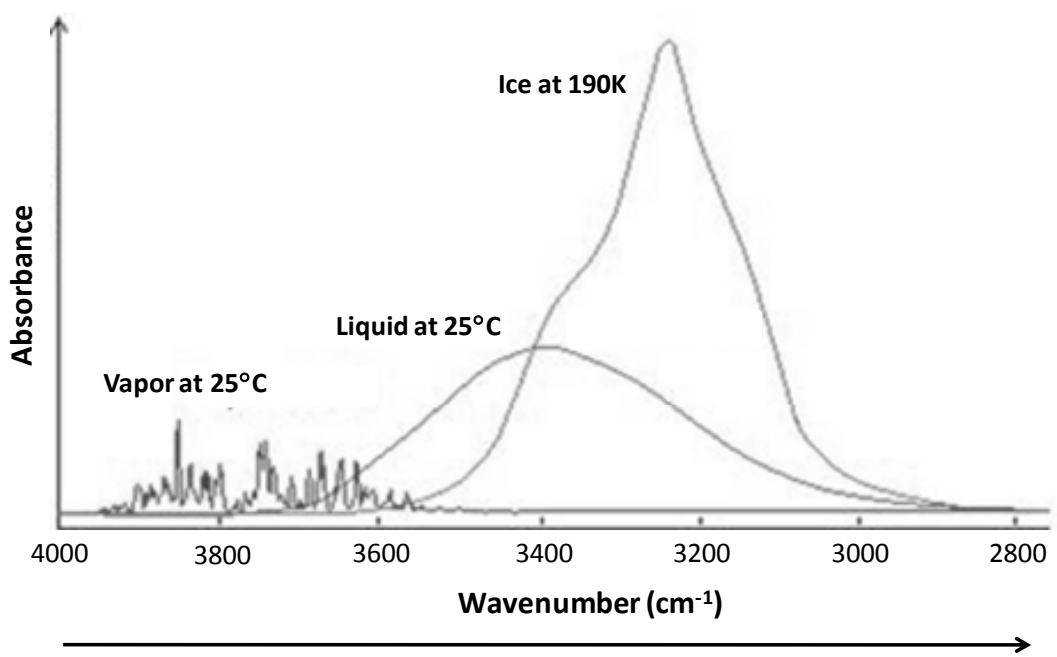

Lower Frequency

Figure 5. Illustration of Water Spectra in Different Physical States, Adapted from Ewing et al. (2003)

hydrogen-bonded (or free) OH. These extremes according to Falk and Ford (1966) do not correspond to distinct molecular species.

The frequency of $\mathrm{OH}$ stretching vibrations is known to decrease in a regular manner with the strength of hydrogen bonding, while frequencies of bending vibrations increase upon hydrogen bonding but the shifts are much smaller (Falk and Ford 1966). Du et al. (1993) used an infrared technique to obtain the $\mathrm{OH}$ stretch vibrational spectra of water at the vapor/water interface. The results presented indicate that more than $20 \%$ of surface water molecules have a non-hydrogen-bonded $\mathrm{OH}$ (free $\mathrm{OH}$ bond) pointing out of the liquid and the other $\mathrm{OH}$, hydrogen bond, pointing into the bulk liquid. The surface vibrational spectra generally exhibit a set of characteristic features indicating that the water molecules form a hydrogen-bonding network which is more well ordered than the bulk. This is more or less expected based on the measured values of the surface tension of water (Shen and Ostroverkhov 2006). Benjamin (1994) also supported the existence of free $\mathrm{OH}$ bonds at the surface and showed that the broad peak near $3400 \mathrm{~cm}-1$, which corresponds to the $\mathrm{OH}$ stretching mode in bulk water, is split into two peaks for water at the surface. The new peak at $3700 \mathrm{~cm}-1$ corresponds to free $\mathrm{OH}$ bonds. At the vapor/liquid interface, the molecules face an environment on the vapor side with no neighboring molecules to complete the hydrogen bonded to. No matter how a water molecule orients itself at the interface, one hydrogen bond with neighboring molecules is necessarily broken. Du et al. (1993) also studied the temperature dependence of the vapor/water interface spectrum, and based on the data presented, there is no significant change over the temperature range from 10 to $80^{\circ} \mathrm{C}$.

\section{EXPERIMENTAL DESIGN}

This section presents the experimental design used in this study as well as a description of the materials used, the specimen fabrication processes and the testing and analysis methodology.

\subsection{Materials and specimens fabrication}

One asphalt binder was selected from the Strategic Highway Research Program (SHRP) Materials Reference Li- brary (MRL), named AAD, that is a PG 58-22 grade California coastal asphalt (Jones IV 1993).

Two specimens' configurations are under evaluation: (i) the infrared depth of penetration that exceeds the thickness of the asphalt film, and (ii) the infrared depth of penetration within the asphalt film, or that does not exceed the thickness of the asphalt film (Figure 6). Up to this point of the investigation, only liquid water has been considered. Figure 7, demonstrates the chamber that holds the substrate, the asphalt film and the water. These configurations were used to investigate the rate of diffusion of semi-ordered water molecules (representing the liquid water) and the random water molecules (representing the water vapor at ambient temperature) through the asphalt film.

In the configuration presented in Figure 6(i), the film thickness has approximately $1 \mu \mathrm{m}$. The samples were prepared using stock asphalt solutions and the spin coater, according to the procedure described by Vasconcelos et al. (2010). In the second configuration, Figure 6(ii), neat asphalt binders were heated up to $100^{\circ} \mathrm{C}$ and pored above the ATR plate (the chamber to hold the water was already attached to the plate). The film thickness could not be measured using the Ellipsometer as the films produced according to configuration (i). Ellipsometer represents a powerful optical tool for studies of organic layers. Given its high precision, this tool can only lead to reliable measurements for films with a maximum of approximately $1 \mu \mathrm{m}$. For this reason, the film thickness in configuration (ii) was estimated based on the gasket thickness, which has approximately $1 \mathrm{~mm}$. In both configurations, the test temperature was kept constant at approximately $24^{\circ} \mathrm{C}$. The procedure to characterize the diffusivity of water through these binders is described in the following subsections.

\subsection{Test method and analysis approach}

As previously described, the FTIR-ATR has the capacity to differentiate water molecules in different physical states. The detailed test method can be found in a previous publication (Vasconcelos et al. 2010). The region of sample collection should cover at least the frequencies where both physical states of water can be observed, between 3000 and $4000 \mathrm{~cm}-1$ (wavenumber). In order to also monitor possible changes in the asphalt binder composition due to the contact with water, the spectra are collected from 900 to 

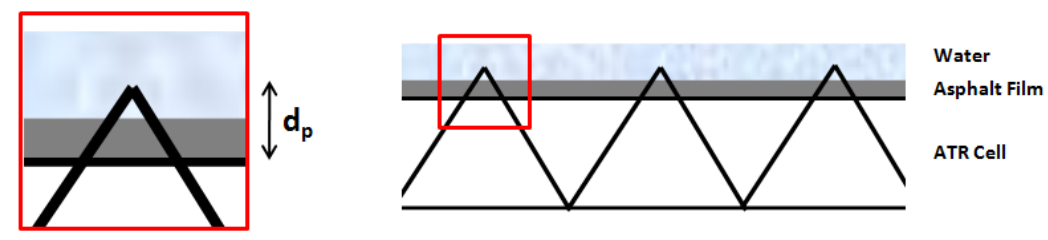

(i)

$d_{p}<$ film thickness
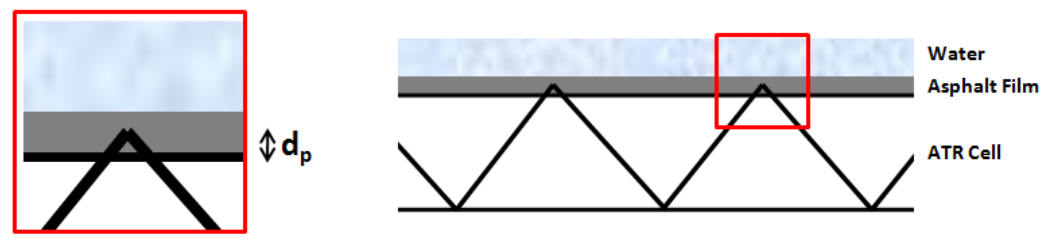

(ii)

Figure 6. Film Thickness Configurations used in the Experiments

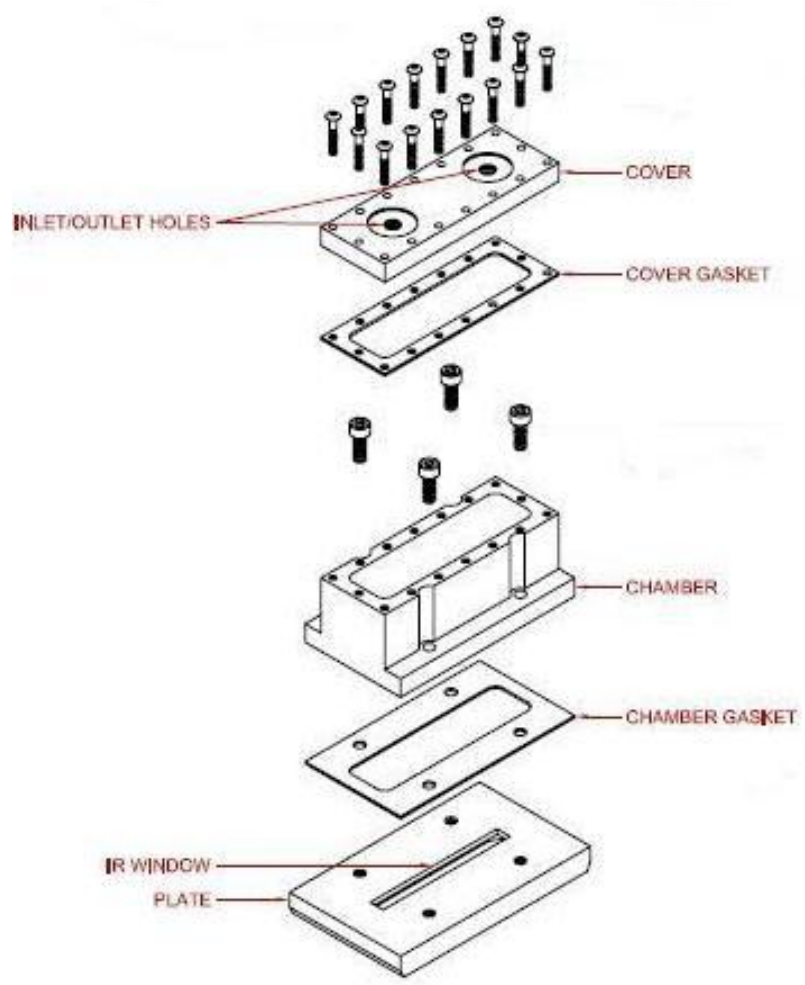

Figure 7. Chamber Designed to Hold the Water during the Test

$4000 \mathrm{~cm}-1$.

According to the diffusivity results obtained using configuration (i) (Vasconcelos et al. 2010), several months will be required before the liquid water signal can be quantified if $1 \mathrm{~mm}$ film thickness is used. The intention in use thicker films is in quantify the water vapor diffusion (maintaining room temperature along the test). The authors believe that the water molecules in the vapor state will diffuse faster than the liquid water. Two regions were evaluated based on the FTIR-ATR spectra acquired: (i) the region representing the liquid water, $3100-3700 \mathrm{~cm}-1$, and (ii) the region representing the water vapor, $3800-4000 \mathrm{~cm}-1$. In FTIRATR, the depth of penetration of the infrared $\left(d_{p}\right)$ is defined as the distance from the IRE surface, over which the magnitude of the penetrating electric field diminishes by a factor of $1 / e$ and is given by the following expression (Griffiths and de Haseth 2007):

$$
d_{p}=\frac{\lambda}{2 \pi n_{2}\left(\sin ^{2} \theta-\left(\frac{n_{2}}{n_{1}}\right)\right)^{1 / 2}}
$$

where, $\lambda$ is the wavelength of the radiation in vacuum, $\theta$ is the angle of incidence, and $n_{1}$ and $n_{2}$ are the refractive indices of the IRE and the sample respectively. Figure 8 illustrates how the infrared depth of penetration varies with the wavenumber.

In the analysis procedure, the initial spectrum of the asphalt binder films (without water) was not subtracted from the subsequent spectra after water was added into the 


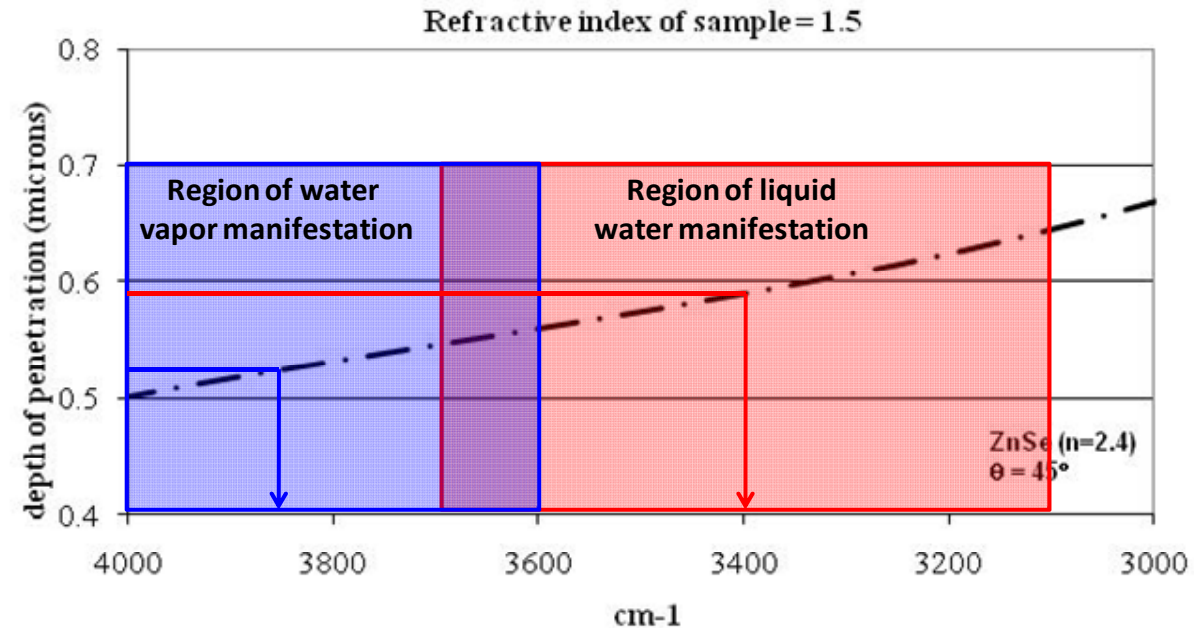

Figure 8. Difference in the Depth of Penetration in Both Regions Evaluated (ZnSe Crystal with $=45$, and Refractive Index of Asphalt Assumed 1.5)

chamber. According to Weis and Ewing (1998), large absorption anomalies can be found in the subtraction of the spectra containing strong absorption lines, that is the case for the water in the vapor (or molecular) form. One cause of this anomaly is the part-per-million errors in the wavenumber of the reference laser, which can introduce large errors in subtraction spectra by introducing error into the wavenumber scale of the spectra (Weis and Ewing 1998). This phenomenon is more pronounced when evaluating the region of moisture (or water vapor) manifestation.

\section{RESULTS}

Figure 9 illustrates the first and the last spectra obtained using both configurations. The sample in configuration (ii) is still being monitored, since the pronounced peak characteristic of liquid water has not yet been observed, and the wa-

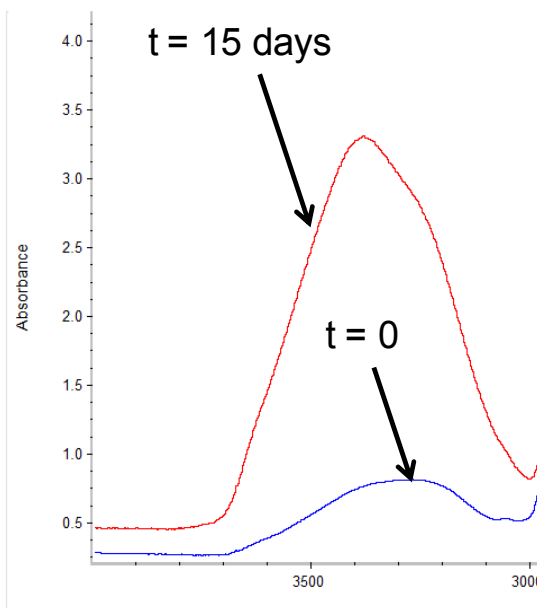

Configuration (i) - $1 \mu \mathrm{m}$ film

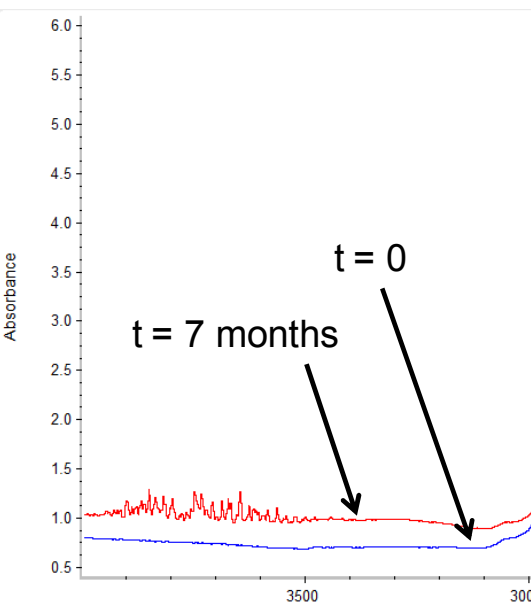

(i)

Configuration (ii) - $1 \mathrm{~mm}$ film

Figure 9. Results Obtained for Film Thickness in Both Configurations Presented in Figure 6 


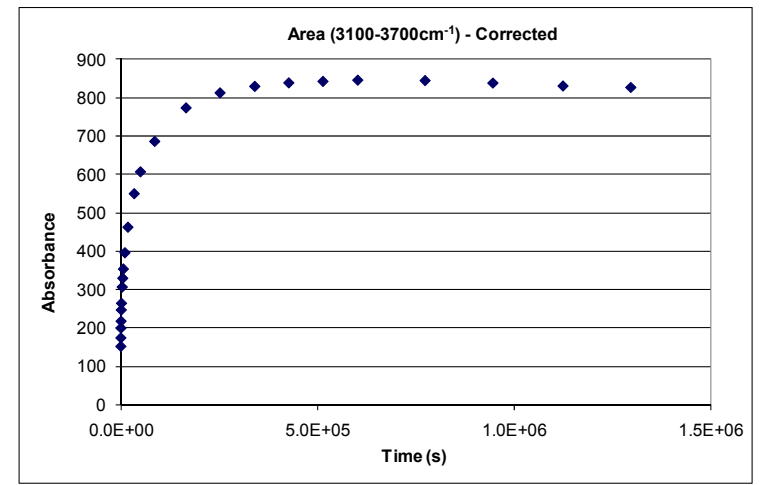

(a)

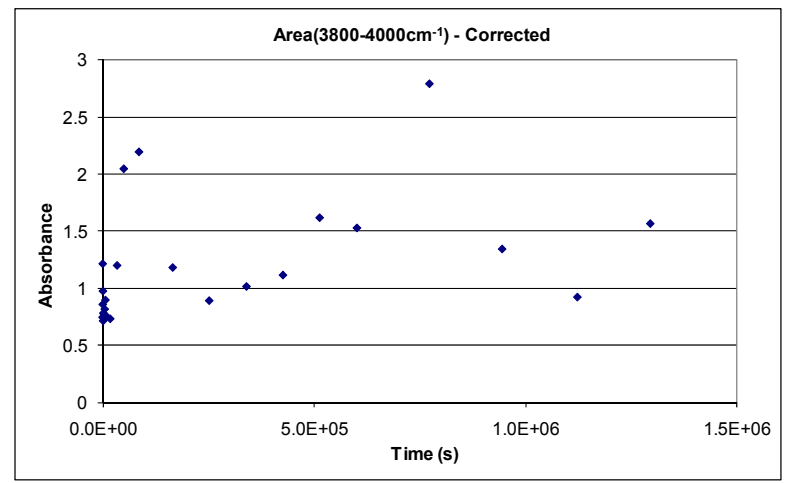

(b)

Figure 10. Results of Absorbance with Time for Asphalt AAD - Configuration (i), (a) Liquid Water Region, and (b) Water Vapor Region

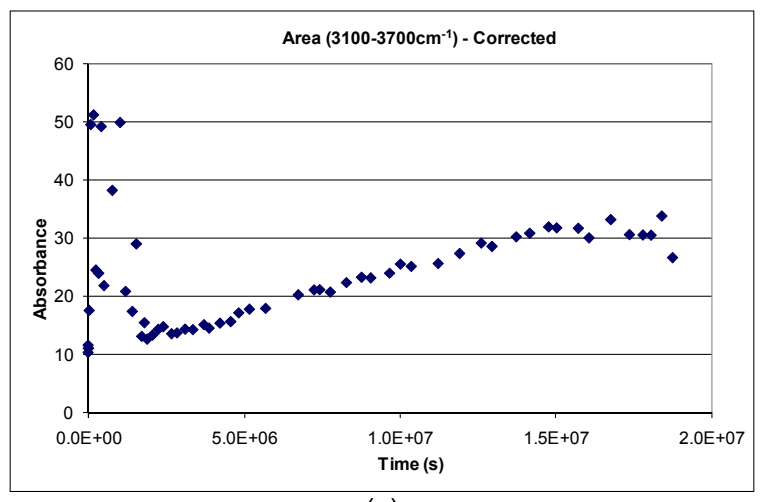

(a)

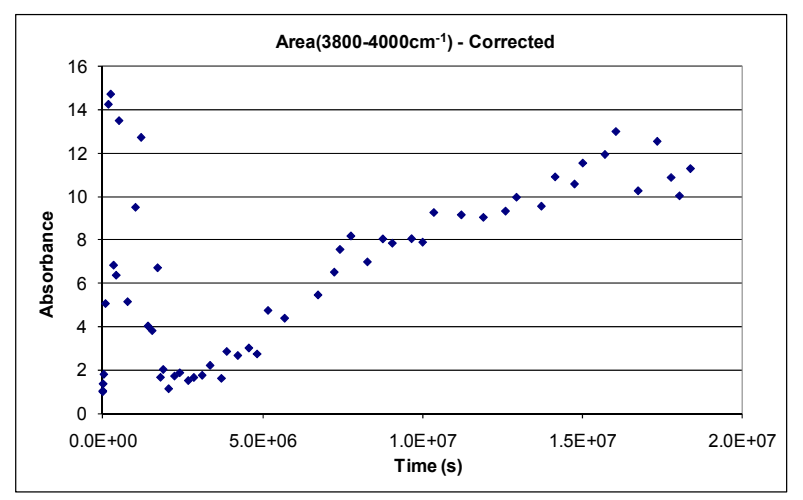

(b)

Figure 11. Results of Absorbance with Time for Asphalt AAD - Configuration (ii), (a) Liquid Water Region, and (b) Water Vapor Region

ter vapor characteristic absorbance, is still changing with time.

Figures 10 and 11 present data of absorbance versus time for configuration conditions (i) and (ii), respectively. Side (a) of the respective figures presents data for liquid water and side (b) presents data for water vapor, in both Figures. These are still preliminary results for one replicate of only one asphalt binder. The objective is to quantify the diffusivity for both water physical states, using the FTIR-ATR technique, for three asphalt binders (already in test).

\section{SUMMARY AND CONCLUSIONS}

Moisture transport through an asphalt mixture is an integral part of the moisture damage mechanism. Moisture damage in an asphalt mixture is a complex process that represents the cumulative effect of moisture transport processes (e.g. diffusion through asphalt binder) and moisture deterioration processes (e.g. loss in mechanical properties of the asphalt binder due to the presence of moisture). In this study, the FTIR-ATR spectroscopy technique was used to investigate the effect of the physical state of water (liquid versus vapor) in its diffusion through the asphalt binder. It is known that the water molecule has distinct arrangement patterns as the physical state change from ice to water to vapor. The FTIR-ATR technique has the ability to differentiate water in different physical states, and this technique was used to quantify molecular water movement into asphalt films. Based on the results obtained, one can observe that the detection of water vapor by the FTIR occurred before the detection of liquid water. These preliminary results give an insight about the influence of the physical state of water in the rate of diffusion into the asphalt films.

\section{ACKNOWLEDGMENTS}

Authors would like to acknowledge FHWA and Asphalt Research Consortium for the funding provided for this study.

\section{REFERENCES}

Arambula, E., S. Caro e E. Masad (2010) Experimental Measurement and Numerical Simulation of Water Vapor Diffusion through Asphalt Pavement Materials. Journal of Materials in Civil Engineering, $A S C E$, v. 22, n.6, p. 588-598. DOI: 10.1061/(ASCE)MT.1943$\underline{5533.0000059}$.

Benjamin, I. (1994) Vibrational Spectrum of Water at the Liquid/Vapor Interface. Physical Review Letters, v. 73, n. 15, p. 2083-2086. DOI: 10.1103/PhysRevLett.73.2083.

Bertie, J. E., H. J. Labbe e E. Whalley (1969) Absorptivity of Ice I in the Range 4000-30 $\mathrm{cm}^{-1}$. The Journal of Chemical Physics, v. 50, n.10, p. 4501-4520. DOI: 10.1063/1.1670922.

Cheng, D. X., D. N. Little, R. L. Lytton e J. C. Holste (2003) Moisture damage evaluation of asphalt mixtures by considering both moisture diffusion and repeated-load conditions. Bituminous Paving Mixtures 2003, v. 1832, p. 42-49. DOI: 10.3141/1832-06.

Du, Q., R. Superfine, E. Freysz e Y. R. Shen (1993) Vibrational spectroscopy of water at the vapor/water interface. Physical Review Letters, v. 70, n. 15, p. 2313-2316. DOI: 10.1103/PhysRevLett. $\underline{70.2313}$.

Ewing, G. E., M. Foster, W. Cantrelll e V. Sadtchenko (2003) Thin Film Water on Insulator Surfaces. Water in Confining Geometries, V. Buch e J. P. Devlin, eds., Springer-Verlag, Berlin, p. 179-211.

Falk, M. e T. A. Ford (1966) Infrared Spectrum and Structure of Liquid Water. Canadian Journal of Chemistry, v. 44, n. 14, p. 16991707. DOI: $10.1139 / \mathrm{v} 66-255$.

Griffiths, P. R. e J. A. de Haseth (2007) Fourier Transform Infrared Spectrometry, Wiley-Interscience, a John Wiley \& Sons Inc. Publication.

Jones IV, D. R. (1993) SHRP Materials Reference Library: Asphalt Cements: A Concise Data Compilation. Report SHRP-A-645, Contract A-001, Strategic Highway Research Program, National Research Council, Washington, DC. 
Kassem, E. A., E. Masad, R. Bulut e R. L. Lytton (2006) Measurements of Moisture Suction and Diffusion Coefficient in Hot Mix Asphalt and their Relationships to Moisture Damage. Transportation Research Record: Journal of the Transportation Research Board, 1970, 45-54. DOI: 10.3141/1970-06.

Kringos, N., A. Scarpas e A. deBondt (2008) Determination of Moisture Susceptibility of Mastic-Stone Bond Strength and Comparison to Thermodynamical Properties. Journal of the Association of Asphalt Paving Technologists, v. 77, p. 435-478.

Nguyen, T., E. W. Byrd, D. Bentz e J. Martin (2005) In Situ Spectroscopy Study of Water at the Asphalt/Siliceous Substrate Interface and Its Implication in Stripping. The Journal of Adhesion, v. 81, p. 1-28. DOI: 10.1080/00218460590904426.

Sasaki, I., A. Moriyoshi, Y. Hachiya e N. Nagaoka (2006) New test method for moisture permeation in bituminous mixtures. Journal of the Japan Petroleum Institute, v.49, n. 1, p. 33-37. DOI: 10.1627/jpi.49.33.

Shen, Y. R. e V. Ostroverkhov (2006) Sum-Frequency Vibrational Spectroscopy on Water Interfaces: Polar Orientation of Water Molecules at Interfaces. Chemical Reviews, v. 106, n. 4, p. 1140-1154. DOI: $10.1021 / \mathrm{cr} 040377 \mathrm{~d}$.

Vasconcelos, K. L., A. Bhasin e D. N. Little (2010) Measurement of Water Diffusion in Asphalt Binders using the FTIR-ATR Technique. Transportation Research Record, v. 2179, p. 29-38. DOI: 10.3141/2179-04.

Wei, J. (2009) Study on the Surface Free Energy of Asphalt, Aggregate and Moisture Diffusion in Asphalt Binder, China University of Petroleum, PhD.

Weis, D. D. e G. E. Ewing (1998) Absorption Anomalies in Ratio and Subtraction FT-IR Spectroscopy. Analytical Chemistry, v. 70, n. 15, 3175-3183. DOI: 10.1021/ac971174a.

Wolf, R. V. (1991) Diffusion In and Through Polymers: Principles and Applications, Hanser Publishers, Munich Viennna New York Barcelona. 